\title{
Untreated heart failure: clinical and neuroendocrine effects of introducing diuretics
}

\author{
JOHN BAYLISS, * MICHAEL NORELL, $†$ RUDOLPH CANEPA-ANSON, * \\ GEORGE SUTTON, $†$ PHILIP POOLE-WILSON* \\ From $\nmid$ Hillingdon Hospital, Uxbridge, Middlesex, and ${ }^{\star}$ the National Heart Hospital and Cardiothoracic \\ Institute, London
}

SUMMARY The clinical and neuroendocrine response to diuretic treatment was assessed at rest and on exercise in 12 patients with heart failure. Before treatment all patients were limited by breathlessness on exercise; one was oedematous. Plasma renin activity and aldosterone were normal but plasma noradrenaline was raised both at rest and on exercise. After one month's treatment with frusemide $(40 \mathrm{mg}$ ) and amiloride $(5 \mathrm{mg})$ weight was significantly reduced by a mean of $3.5 \mathrm{~kg}$ and exercise capacity had doubled. Plasma noradrenaline fell to normal at rest but remained abnormally raised on exercise. Plasma renin activity and aldosterone increased significantly both at rest and on exercise.

Diuretics bring about a considerable clinical improvement in patients with chronic heart failure but they stimulate the renin-angiotensin system. Activation of the renin-angiotensin system in moderate heart failure occurs as a response to diuretic treatment rather than as a result of the disease process itself.

Although diuretics are widely used in the treatment of chronic heart failure, the initial effects of treatment have rarely been studied. In recent years the importance of the neuroendocrine response to heart failure has been emphasised and many trials have been undertaken with drugs that oppose activation of the sympathetic and renin-angiotensin systems. Angiotensin converting enzyme (ACE) inhibitors in particular have been shown to be beneficial in patients with moderate to severe heart failure already treated with diuretics. ${ }^{1}$ Diuretics are known to activate the renin-angiotensin system; so a raised renin activity in patients with heart failure may be a consequence of treatment rather than of heart failure itself. The benefit of ACE inhibitors may occur partly because these drugs offset this effect of diuretics.

We have studied untreated patients presenting with breathlessness due to chronic heart failure and have assessed clinical and neuroendocrine variables at rest and on upright exercise before and one month after the introduction of diuretics (frusemide and

Requests for reprints to Professor P A Poole-Wilson, Cardiothoracic Institute, 2 Beaumont Street, London W1N 2DX.

Accepted for publication 15 September 1986 amiloride). The purpose of the study was to determine whether neuroendocrine systems were activated in untreated heart failure or whether activation was secondary to treatment.

\section{Patients and methods}

Twelve patients (mean age 59 years (range 22-75), five female) were studied. The aetiology of heart failure was coronary artery disease without recent myocardial infarction in six patients, dilated cardiomyopathy in five, and mitral valve disease in one. No patient had hypertensive or renal disease.

All patients had been referred with breathlessness on moderate exertion (New York Heart Association class II-III) but had received no treatment. Patients had had symptoms for between one and six months. The patient with mitral valve disease had been on digoxin for control of atrial fibrillation, and the drug was continued. No other cardiac drugs were being taken by these patients. Five patients had sinus tachycardia at rest. The jugular venous pressure was elevated in four and a third heart sound was heard in seven. Mild pitting ankle oedema was present in one patient. Four patients were in atrial fibrillation. All patients had cardiomegaly by chest $x$ ray (cardiothoracic ratio $>0.55$ ) or increased left ventricular 


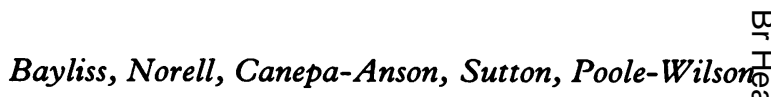

end systolic diameter $(>5.5 \mathrm{~cm})$ by echocardiography. All patients had radiological evidence of pulmonary venous hypertension.

Patients were initially assessed after resting for at least one hour. Four patients had been admitted to hospital. The remainder were studied as outpatients. Nude weight was measured. Heart rate was determined from an electrocardiogram. Venesection for neuroendocrine measurements was performed with the patient supine (see below). Patients performed a maximal treadmill exercise test at low workloads that increased in six-minute stages. ${ }^{2}$ The electrocardiogram was observed continuously and venesection was repeated at maximal exercise. One patient was unable to walk on the treadmill because of breathlessness.

Treatment with frusemide $40 \mathrm{mg}$ and amiloride $5 \mathrm{mg}$ (Frumil 1 tablet) once daily was started. Inpatients were discharged after treatment. All patients were reviewed after four weeks. One patient suffered a transient cerebral ischaemic attack and was not restudied. The remaining 11 patients were reassessed on treatment at least four hours after their medication. Clinical and neuroendocrine measurements were made at rest and after maximal treadmill exercise. The exercise test was not repeated in the patient who had been unable to walk on the treadmill.

Venous blood for neuroendocrine measurements was taken into chilled tubes, centrifuged immediately, and the plasma stored at $-70^{\circ} \mathrm{C}$ until assay. Plasma renin activity and aldosterone were measured by radioimmunoassay, ${ }^{34}$ (normal range $0.5-2.5 \mathrm{ng} / \mathrm{ml} / \mathrm{h}(0.39-1.9 \mathrm{nmol} / \mathrm{l} / \mathrm{h})$ and $100-600$ $\mathrm{pmol} / \mathrm{l}$, respectively). Plasma noradrenaline was measured by radioenzymatic assay, with a modification of the method of Henry et al (normal range $200-800 \mathrm{pg} / \mathrm{ml}(1 \cdot 2-4 \cdot 7 \mathrm{nmol} / \mathrm{l})) .^{5}$
Mean values (SE) are given for weight, heart rate and exercise time. Hormonal values were distributed: normally only after logarithmic transformation, so geometric means (95\% confidence limits) are givero for these results. Statistical analysis was by analysis of variance.

\section{Results}

The clinical features of patients before treatmen $\vec{P}$ have been described above. After one month of treatment with diuretics the signs of heart failure were no longer present. In no patient was the jugula venous pressure elevated or an additional hearter sound heard. Weight was reduced by a mean of $3.64 \mathrm{~kg}(\mathrm{p}=0.0003)$ (table). Resting heart rate fell $(p=0.03)$. Heart rate at maximal exercise remained unchanged. Mean maximal treadmill time before treatment was $9 \cdot 1 \mathrm{~min}$, corresponding on our exer $\overrightarrow{\vec{C}}$ cise protocol to an oxygen consumption of approxi $\frac{0}{5}$ mately $17 \mathrm{ml}$ of oxygen $/ \mathrm{kg} / \mathrm{min}$. Maximal treadmil exercise time increased by $93 \%(p=0.007)$ (fig 1$) \leqslant$ Whereas all patients had been limited by breath $\overrightarrow{0}$ lessness on exercise before treatment, five patients were limited more by fatigue than by breathlessness when they exercised on treatment.

Plasma renin activity and plasma aldosterone in untreated patients were normal both at rest and at maximal exercise, but these values increased too abnormal concentrations after diuretic treatmen? $(p<0.0007)$ (table and figs 2 and 3). Plasma nor-0ํำ adrenaline in untreated patients was raised at res $\zeta$ and at maximal exercise. After diuretic treatmen plasma noradrenaline fell to normal at rest $(p=$ 0.005 ), but remained abnormally raised on exercise (table and fig 4). The reduction in resting heart rate during diuretic treatment correlated with the reduction in resting plasma noradrenaline $(r=0.64, p=$

Table Clinical measurements (mean $(S E))^{\star}$ and hormonal values (geometric mean $(95 \%$ confidence interval) $)+$ before and after one month's treatment with frusemide $40 \mathrm{mg}$ and amiloride $5 \mathrm{mg}$

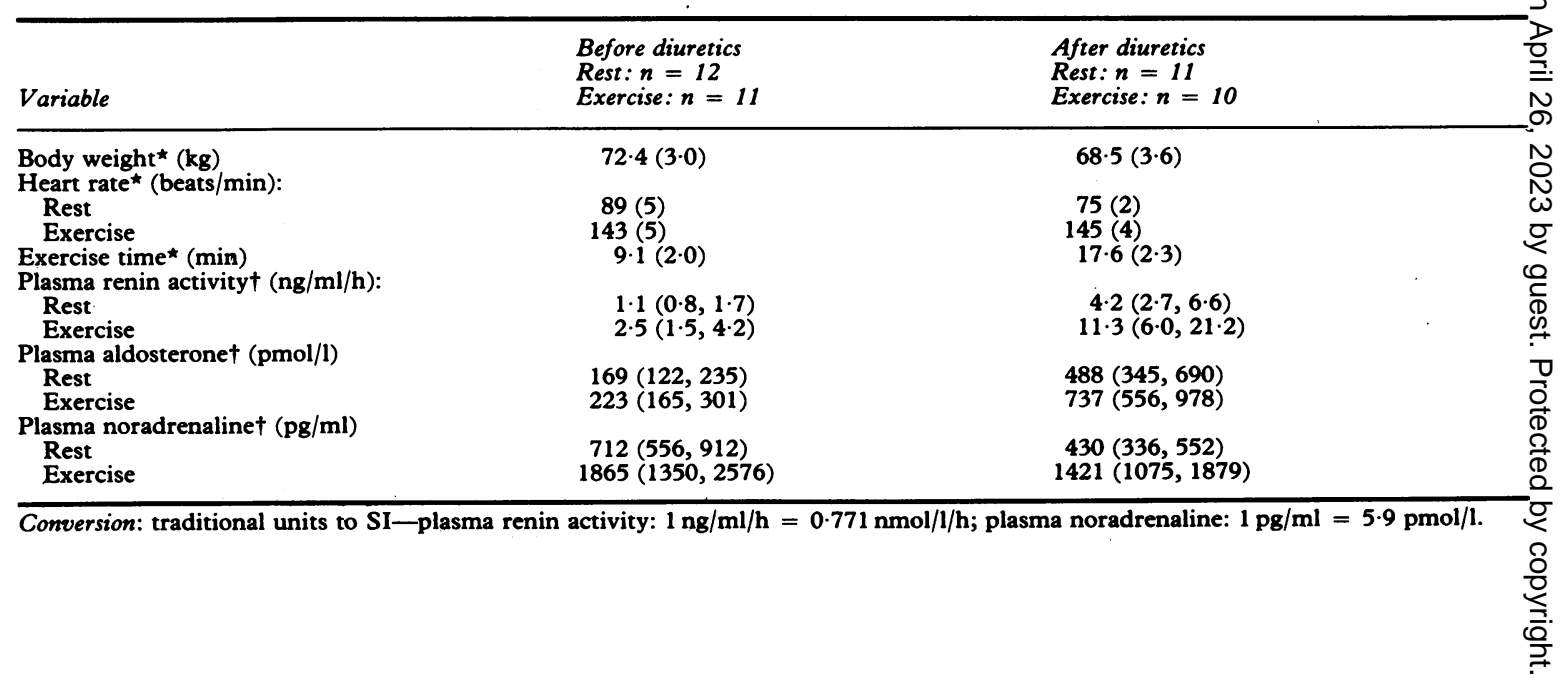


Untreated heart failure: clinical and neuroendocrine effects of introducing diuretics

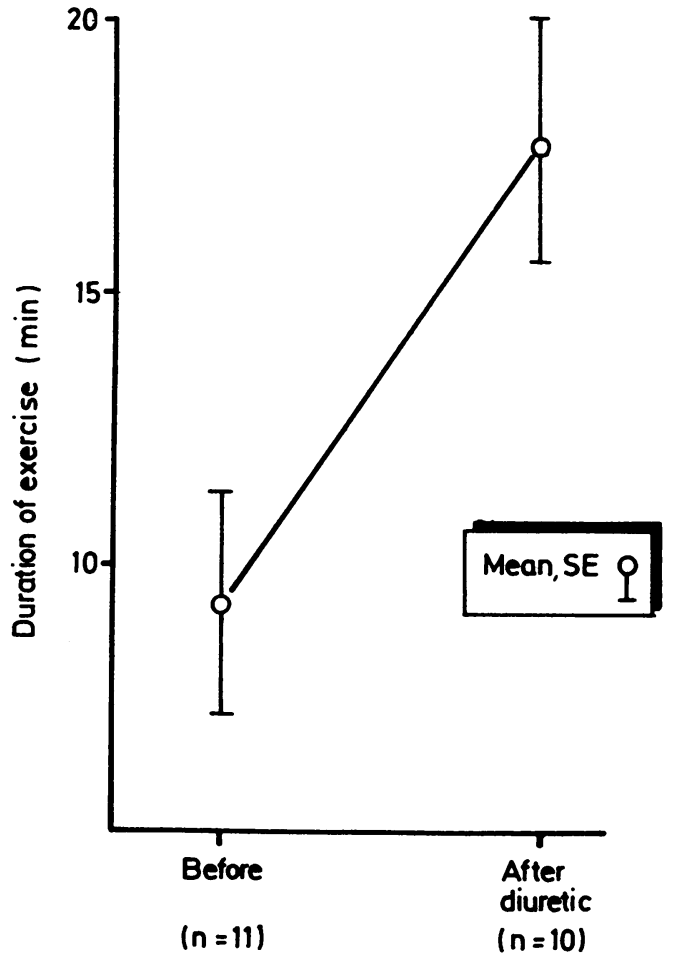

Fig 1 Maximal treadmill exercise time in patients before and after diuretic treatment
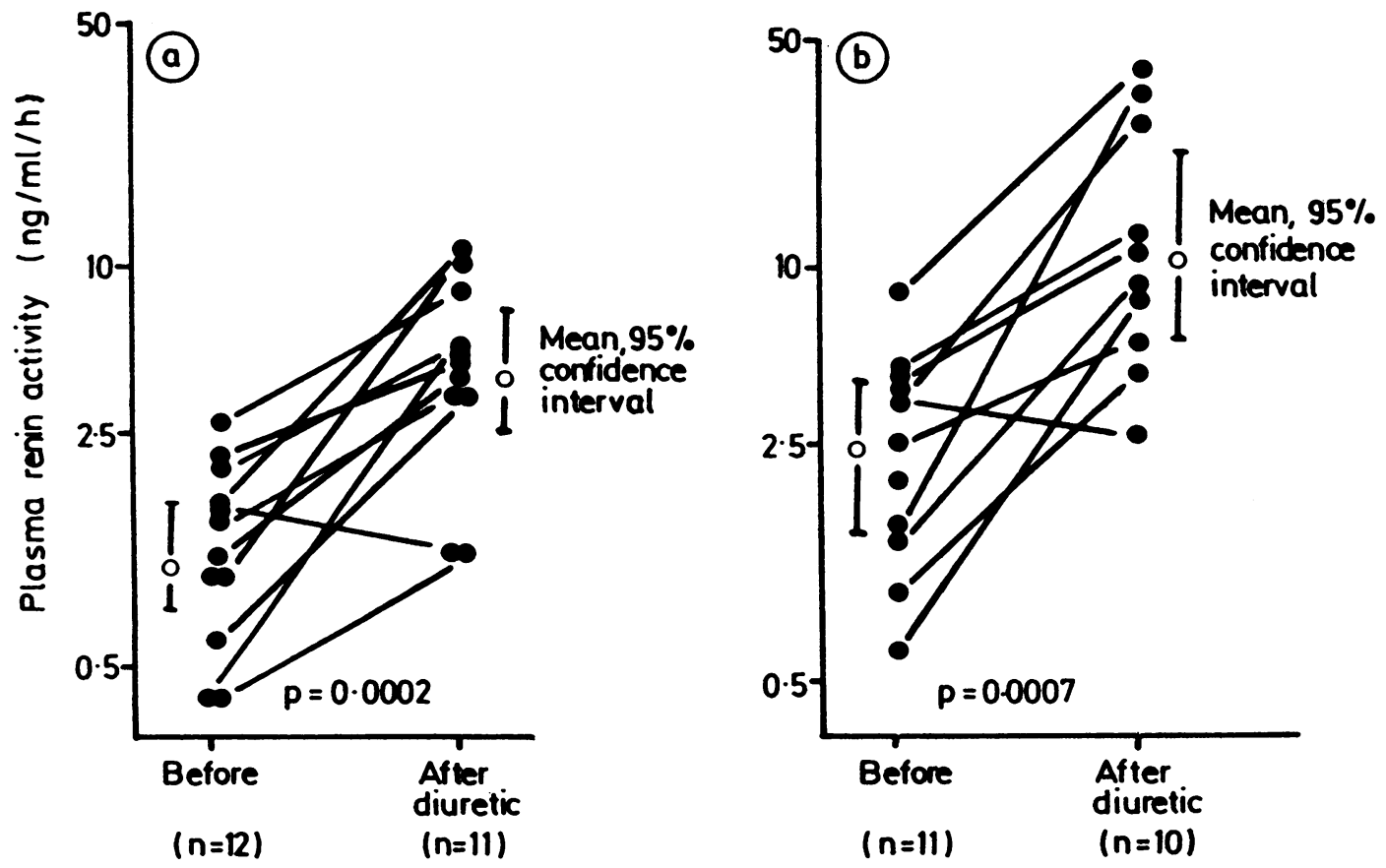

Fig 2 Plasma renin activity at rest (a) and at maximal exercise (b) in patients before and after diuretic treatment. Conversion: traditional units to $S I$-renin: $1 \mathrm{ng} / \mathrm{ml} / \mathrm{h}=0.771 \mathrm{nmol} / \mathrm{l} / \mathrm{h}$. 

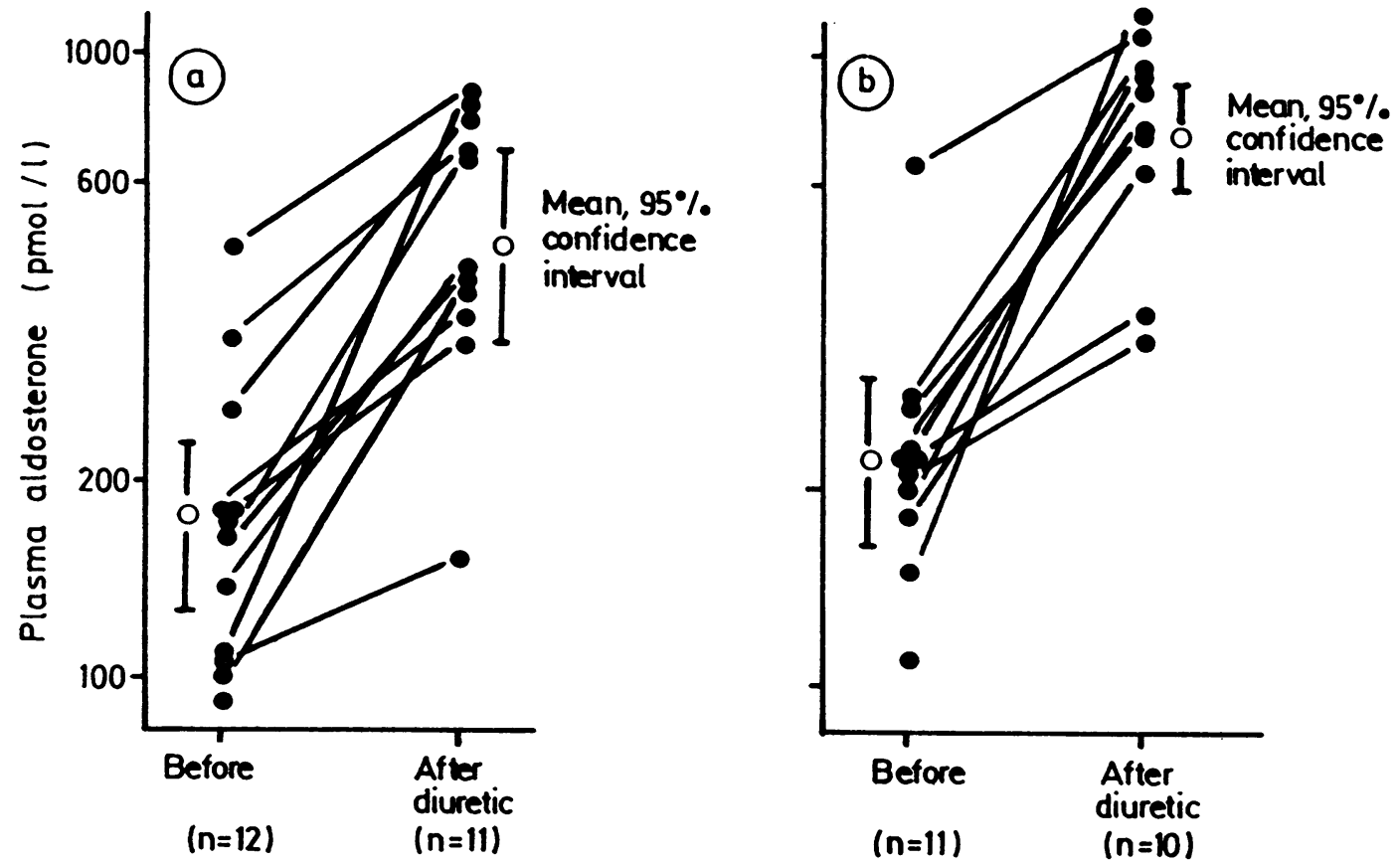

Fig 3 Plasma aldosterone at rest ( $a$ ) and at maximal exercise $(b)$ in patients before and after diuretic treatment.

(a)

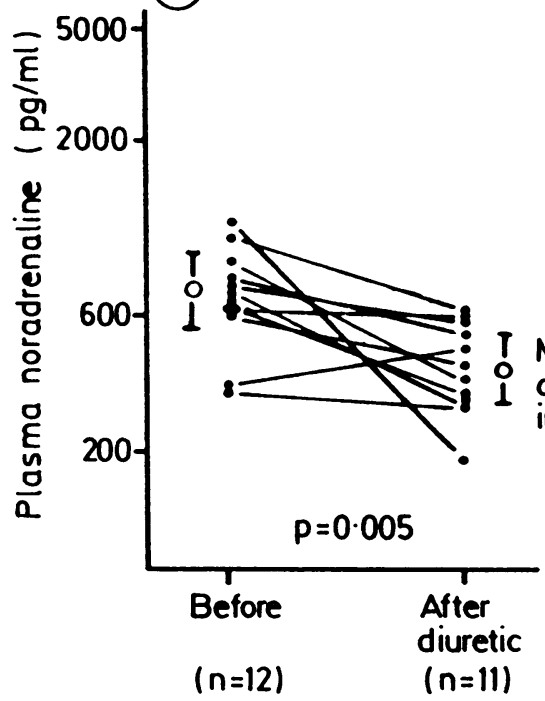

Mean, $95 \%$ confidence interval (b)

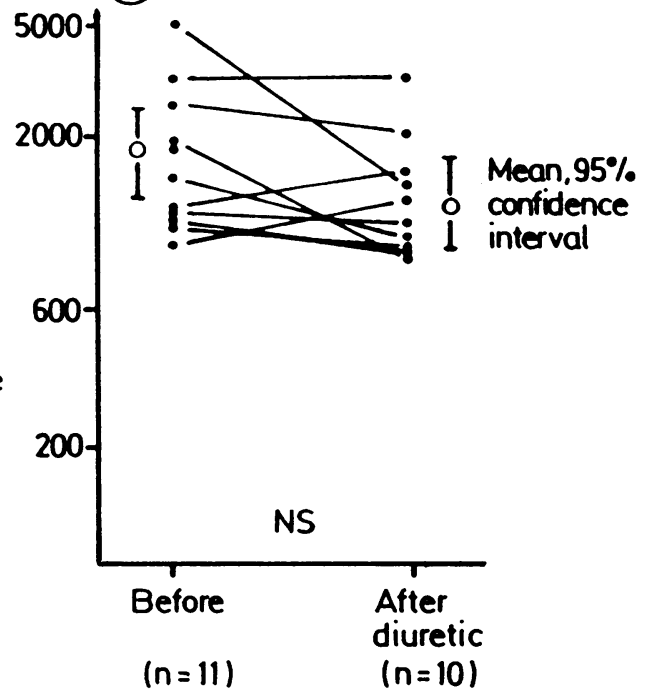

Fig 4 Plasma noradrenaline at rest $(a)$ and at maximal exercise $(b)$ in patients before and after diuretic treatment. Conversion: traditional units to $S I-$ noradrenaline: $1 \mathrm{pg} / \mathrm{ml}=5.9 \mathrm{pmol} / \mathrm{l}$.

$0.03)$, suggesting that plasma noradrenaline values were a measure of the degree of sympathetic activation.

Neuroendocrine variables in patients with heart failure due to coronary artery disease did not differ from those with dilated cardiomyopathy before 0 treatment, and the response to diuretic treatment was similar. In the patient with mitral valve disease, $\stackrel{\mathbb{D}}{\stackrel{\oplus}{\oplus}}$ plasma renin activity fell after diuretic treatment $\stackrel{\mathbb{\Omega}}{\varrho}$ both at rest and on exercise, though plasma al- $\bar{\sigma}$ 
dosterone was increased by diuretic treatment in this patient.

\section{Discussion}

In an early study of the hormonal response to chronic heart failure, Brown et al found that nine out of 13 patients with untreated left ventricular failure had normal or low plasma renin activity at rest. ${ }^{6}$ Our study provides further evidence that not all untreated patients in heart failure have raised plasma renin activity or aldosterone concentrations at rest. We have also shown that the stimulus of maximal upright exercise causes only a modest increase in these hormones.

It is probable that the untreated patients in the present study had expanded circulatory volumes, as suggested by elevation of the venous pressure in four, peripheral oedema in one, and a loss of weight of more than $3 \mathrm{~kg}$ on treatment. In the presence of such circulatory expansion the finding of values for plasma renin activity at the upper end of the normal range does suggest some activation of this system. The present patients had only "moderate heart failure". In more severe untreated heart failure it is possible that activation of the renin-angiotensin system might be greater, but most previous studies showing significant activation of the renin-aldosterone system in heart failure are difficult to interpret as they have been undertaken in patients who not only had severe heart failure but were also being treated with diuretics. In such cases, raised concentrations of plasma renin and aldosterone could be due to the heart failure itself, to diuretic treatment, or to both.

In the present study plasma noradrenaline was raised both at rest and on exercise in untreated patients. Activation of the sympathetic system, as assessed by plasma noradrenaline concentration, appears to relate to the degree of left ventricular dysfunction in heart failure. ${ }^{78}$ In our patients with "moderate" heart failure the increase in plasma noradrenaline was not associated with an increase of plasma renin activity, suggesting that the earliest neuroendocrine response to heart failure is activation of the sympathetic system alone.

Diuretic drugs are firmly established as the initial treatment for patients with chronic heart failure. Yet few studies have reported the long term effects of starting such treatment. In the only trial that has assessed patients on exercise, Stampfer et al found that the use of thiazide diuretics in patients with established heart failure caused a diuresis of $3.4 \mathrm{~kg}$, resulting in clinical improvement and a slight increase in exercise capacity. ${ }^{9}$ In Stampfer et al's study cardiac output was reduced at rest $(-20 \%)$ and on exercise $(-10 \%)$ in all patients and this was attributed to a fall in ventricular filling pressure. ${ }^{9}$ The ventricular filling pressure was reduced either as a result of venodilatation or because of a reduced circulating volume secondary to a diuresis. Several other studies ${ }^{10-12}$ have demonstrated similar short term haemodynamic effects at rest. Such reduction in cardiac output with the use of diuretics is often associated with immediate stimulation of the reninangiotensin system. ${ }^{13}$ Ikram et al ${ }^{14}$, Nicholls et al ${ }^{15}$, and Knight et al ${ }^{16}$ have shown that renin, angiotensin, and aldosterone continue to increase over several days as "dry weight" is achieved and cardiac output falls.

The present study has shown that the introduction of frusemide with amiloride in patients with untreated heart failure caused a pronounced increase in plasma renin activity and aldosterone at rest and on exercise. Despite this stimulation of the reninangiotensin-aldosterone system there was clinical improvement and an increase in exercise capacity over a period of one month. Clinical improvement was associated with a reduction in sympathetic activity and plasma noradrenaline at rest but not on exercise.

Our study is complementary to that of Stampfer et $a l^{9}$ on the effects of thiazide diuretics in heart failure. Although we did not make haemodynamic measurements, it is likely that the haemodynamic effects of treatment were similar to those reported by Stampfer $e t a l^{9}$, with reductions in left ventricular filling pressures and cardiac output at rest and on exercise. The initial improvement of breathlessness and increase in exercise capacity in our patients may have been due to relief of pulmonary congestion, but other mechanisms may be important in the longer term because breathlessness and maximal exercise capacity do not in general correlate with left ventricular filling pressure ${ }^{17}$ in patients with chronic heart failure treated with diuretics. An alternative explanation for the increase in exercise capacity would be that despite an overall reduction in cardiac output, the diuresis brought about a greater fall in arteriolar resistance in skeletal muscle on exercise and thus increased muscle blood flow.

These results have an important clinical implication. It is possible that a further increase in exercise capacity might have been achieved in these untreated patients if an angiotensin converting enzyme inhibitor had been prescribed with the diuretic to limit the increase of renin activity. Prevention of the diuretic induced stimulation of the renin-angiotensin system may be important in the long term management of chronic heart failure, since stimulation of the renin-angiotensin system, causing vasoconstriction and fluid retention, is deleterious to the failing heart and circulation. ${ }^{18} 19$ 
The obvious clinical benefits of diuretics in chronic heart failure may mask more subtle, possibly adverse, neuroendocrine changes, which may have important long term consequences in the progression of the disease process itself.

\section{References}

1 Lipkin DP, Poole-Wilson PA. Treatment of chronic heart failure: a review of recent drug trials. $\mathrm{Br} \mathrm{Med} \mathcal{F}$ 1985;291:993-6.

2 Lipkin DP, Perrins J, Poole-Wilson PA. Respiratory gas exchange in the assessment of patients with impaired ventricular function. $B r$ Heart $\mathcal{F}$ 1985;54: 321-8.

3 Roulston JE, MacGregor GA. Measurement of plasma renin activity by radioimmunoassay after prolonged cold storage. Clin Chim Acta 1978;88:45-8.

4 Jones VHT, Wilson GA. Determination of aldosterone in biological fluids. In: Reid E, ed. Assay of drugs and other trace compounds in biological fluids. Methodological development in biochemistry. Vol 5. Amersham: Elsevier, North Holland, 1976:149-58.

5 Henry DP, Starman BJ, Johnson DG. A sensitive radioenzymatic assay for norepinephrine in tissue and plasma. Life Sci 1975;16:375-84.

6 Brown JJ, Davies DL, Johnson VW, Lever AF, Robertson JIS. Renin relationships in congestive heart failure, treated and untreated. Am Heart $\mathcal{f}$ 1970;80:329-42.

7 Goldstein DS. Plasma norepinephrine as an indicator of sympathetic neural activity in clinical cardiology. Am $\mathcal{F}$ Cardiol 1981;48:1147-54.

8 Francis GS, Goldsmith SR, Cohn JN. Relationship of exercise capacity to resting left ventricular performance and basal plasma norepinephrine levels in patients with congestive heart failure. Am Heart $\mathcal{f}$ 1982;104:725-31.

9 Stampfer M, Epstein SE, Beiser GD, Braunwald E.
Hemodynamic effects of diuresis at rest and during intense upright exercise in patients with impaired. cardiac function. Circulation 1968;37:900-11.

10 Dikshit K, Vyden JK, Forrester JS, Chatteriee $\mathrm{K}_{2} \stackrel{\oplus}{-}$ Prakash R, Swan HJC. Renal and extrarenal hemodynamic effects of furosemide in congestive heart failure after acute myocardial infarction. $N$ Engl $\mathcal{F}_{\vec{D}}$ Med 1973;288:1087-90.

11 Lal S, Murtagh JG, Pollock AM, Fletcher E, Binnion PF. Acute haemodynamic effects of frusemide in patients with normal and raised left atrial pressures. $\overrightarrow{0}$ Br Heart $\mathcal{f}$ 1969;31:711-7.

12 Nelson GIC, Silke B, Ahuja RC, Hussain M, Taylor $\vec{\omega}$ SH. Haemodynamic advantages of isosorbide dinitrate over frusemide in acute heart failure following myocardial infarction. Lancet 1983;i:730-2.

13 Francis GS, Siegel RM, Goldsmith SR, Olivari MT, Levine TB, Cohn JN. Acute vasoconstrictor response to intravenous furosemide in patients with chronic congestive heart failure. Activation of the neurohumoral axis. Ann Intern Med 1985;103:1-6.

14 Ikram H, Chan W, Espiner EA, Nicholls MG. Haemo-ฏ dynamic and hormone responses to acute and chronic frusemide therapy in congestive heart failure. Cling Sci 1980;59:443-9.

15 Nicholls MG, Espiner EA, Donald RA, Hughes H. Aldosterone and its regulation during diuresis in $V$ patients with gross congestive heart failure. $\mathrm{Clin} \mathrm{Sci}$ Mol Med 1974;47:301-15.

16 Knight RK, Maill PA, Hawkins LA, Dacombe J, Edwards CRW, Hamer J. Relation of plasmaŌ aldosterone concentration to diuretic treatment in patients with severe heart disease. Br Heart $\mathcal{f}^{\mathbb{\Phi}}$ 1979;42:316-25.

17 Lipkin DP, Poole-Wilson PA. Symptoms limiting exercise in chronic heart failure. $\mathrm{Br}$ Med $\boldsymbol{f}_{-}$ 1986;292:1030-1.

18 Cohn JN, Levine TB, Francis GS, Goldsmith S. Neurohumoral control mechanisms in congestive $\underset{\mathbb{\Phi}}{\supset}$ heart failure. Am Heart $\mathcal{F}$ 1981;102:509-14.

19 Cohn JN. Vasodilator therapy for heart failure. The influence of impedance on left ventricular per- 3 formance. Circulation 1973;48:5-8. 